\title{
Identifikasi Hazard dari Hasil Data Free Span pada Jalur Pipa Bawah Laut Lapangan Bekapai Menggunakan Data Multibeam Echosounder dan Side Scan Sonar
}

\author{
MUHAMMAD BIANA RAVENSKA, NI MADE RAI RATIH CAHYA PERBANI
}

\author{
Jurusan Teknik Geodesi \\ FTSP - Institut Teknologi Nasional, Bandung \\ Email: ravenskabiana@yahoo.com
}

\begin{abstract}
ABSTRAK
Lapangan Bekapai merupakan salah satu lapangan minyak yang memproduksi dan mendistribusikan minyak dan gas alam lewat pipa bawah laut. Untuk itu perlu dilakukan inspeksi secara berkala untuk meminimalkan terjadinya hazard baik yang berasal dari proses instalasi maupun dari proses operasi, di antaranya berupa free span. Penelitian ini menggunakan data multibeam echosounder (MBES) untuk mendapatkan data panjang dan posisi free span, sedangkan data side scan sonar (SSS) untuk interpretasi objek pipa dan perkiraan tinggi free span. Profil yang dibangun dari data MBES digunakan untuk memastikan adanya cekungan pada lokasi free span yang terdeteksi. Kriteria identifikasi hazard berupa free span pada jalur pipa bawah laut menggunakan DNV RP F-105 dengan panjang dan tinggi maksimum yang diperbolehkan adalah 14 meter dan 0,6 meter. Free span maksimum yang terdeteksi di lokasi penelitian memiliki panjang 9,2 meter dan tinggi 0,24 meter, yang masih dikategorikan aman atau tidak terjadi hazard pada pipa bawah laut di lokasi penelitian.
\end{abstract}

Kata kunci: free span, multibeam echosounder, side scan sonar

\begin{abstract}
Bekapai Field has been known as one of the oil fields which produce and transport oil and natural gas through the subsea pipelines. It becomes so important to inspect periodically for minimizing the coming out of hazards, either during installation or operation process. One of the hazards is a free span. This research uses multibeam echosounder (MBES) data to specify the length and the position of free span, while side scan sonar (SSS) data is used to interpret the object of pipeline and to estimate the height of free span. Profiles that are builded from MBES data are used to ascertain the existence of a basin under the detected free span. DNV RP F-105 as the criteria of hazard identification for free span requires the maximum of length and height be allowed are 14 meters and 0.16 meters. The maximum free span detected at the research area has 9.2 meters length and 0.24 meters height, thus it can be stated as a safe condition category or there is no subsea pipelines hazards at the research area.
\end{abstract}

Keywords: free span, multibeam echosounder, side scan sonar 


\section{PENDAHULUAN}

Suatu instalasi pipa bawah laut memerlukan inspeksi secara berkala untuk meminimalkan terjadinya hazard yang ditimbulkan dari kondisi alam maupun kesalahan dari manusia. Menurut Hanimadhani (2016), beberapa permasalahan teknis pada jaringan pipa bawah laut muncul terutama terkait dengan kondisi alam dan buatan, seperti: kondisi geologi yang berhubungan dengan jalur pipa yang memotong patahan, kondisi kegempaan, morfologi dasar laut yang tidak rata (berundulasi), sebaran sedimen permukaan dasar laut, keberadaan infrastruktur jaringan kabel bawah laut di sekitar lokasi penggelaran pipa yang bersilangan dengan jalur pipa, kondisi arus dan gelombang yang cukup besar, kegiatan pelayaran, kegiatan nelayan, dan penggelaran pipa yang tidak sesuai dengan ketentuan perundangan yang berlaku dapat menyebabkan instalasi pipa bawah laut menjadi rawan akibat aktivitas geologi yang membahayakan (geohazard). Aspek-aspek ini akan berpengaruh secara langsung terhadap stabilitas pipa di dasar laut, terutama terhadap kemungkinan terjadinya bentang bebas pada pipa (free span) dalam gerakan mendatar dan vertikal, kegagalan akibat lelah (fatigue), dan pembengkokan pipa (buckling). Terganggunya stabilitas pipa di dasar laut akan berpengaruh secara langsung ataupun tidak langsung terhadap terjadinya kegagalan struktur pada jaringan pipa. Salah satu hal yang harus diperhatikan adalah bentang bebas (free span) atau bagian pipa yang tidak bertumpu.

Menurut Erwanti dkk. (2016) free span bawah laut adalah suatu kondisi di mana bentangan pipa dengan panjang tertentu memiliki jarak (gap) terhadap seabed. Free span terjadi akibat ketidakrataan (uneven) permukaan dasar laut yang tidak memenuhi kurvatur natural dari pipa tersebut sehingga bentang pipa akan menggantung. Selain itu, free span juga dapat terjadi jika pada jalur pipa tersebut memiliki persimpangan (crossing) dengan pipa atau kabel lain di bawah laut. Berdasarkan Standar Internasional DNV RP F-105 faktor-faktor terjadinya free span antara lain disebabkan oleh ketidakrataan dasar laut dan perubahan kondisi dasar laut akibat sand scouring dan strudel scours (Veritas Offshore Technology and Services $A / S, 2006)$. Informasi panjang dan tinggi free span dapat diperoleh melalui survei inspeksi dengan memanfaatkan instrumen hidroakustik seperti multibeam echosounder dan side scan sonar. Menurut Prayoga (2013) identifikasi hazard harus dilakukan secara sistematis dan harus dapat mencakup semua kemungkinan terjadinya bahaya yang mungkin terjadi pada pipa bawah laut.

Salah satu penyebab terjadinya hazard, yaitu adanya free span pada pipa bawah laut. Untuk mengidentifikasi ada atau tidaknya hazard dapat dilakukan dengan cara pemodelan tiga dimensi dari penggabungan data multibeam echosounder dan citra side scan sonar. Menurut Erwanti dkk. (2016) data dari multibeam echosounder dimanfaatkan untuk survei batimetri, yaitu survei yang dimaksudkan untuk mendapatkan data kedalaman dan topografi dasar laut termasuk lokasi dan luasan objek-objek yang mungkin membahayakan, sedangkan data dari side scan sonar dimanfaatkan untuk interpretasi objek secara kualitatif maupun kuantitatif.

Menurut Sumarsono (2011) Bekapai adalah salah satu lapangan minyak yang ditemukan oleh Total E\&P Indonesie pada tahun 1972. Penemuan Lapangan Bekapai ini merupakan tonggak awal kehadiran Total E\&P Indonesie di Indonesia yang terletak di lepas pantai Provinsi Kalimantan Timur dengan luas area 20 kilometer persegi seperti yang dapat dilihat pada Gambar 1. Bekapai telah berhasil memproduksi minyak sejak bulan Juli 1974 dan sampai saat ini telah beroperasi selama 37 tahun. Prestasi ini terwujud berkat hasil kerja keras yang terus menerus dari tim Total E\&P Indonesie yang ahli dan berpengalaman dengan menggunakan teknologi tinggi. Pada akhir bulan Januari 2011 Bekapai berhasil 
mencatatkan produksi minyak yang luar biasa dengan akumulasi sebanyak 200 juta barel minyak.

Menurut Wibisono (2016) berdasarkan data yang dihimpun Tempo, pengalihan kepada PT Pertamina sudah secara resmi dilakukan melalui penandatanganan kontrak kerja sama pengelolaan Blok Mahakam, yang berlangsung di Hotel Dharmawangsa, Jakarta, pada Selasa, 29 Desember 2015. Pengelolaan selama 20 tahun mulai 1 Januari 2018 hingga 31 Desember 2038 ditangani anak perusahaan PT Pertamina, PT Pertamina Hulu Mahakam berkaitan dengan participation interest.

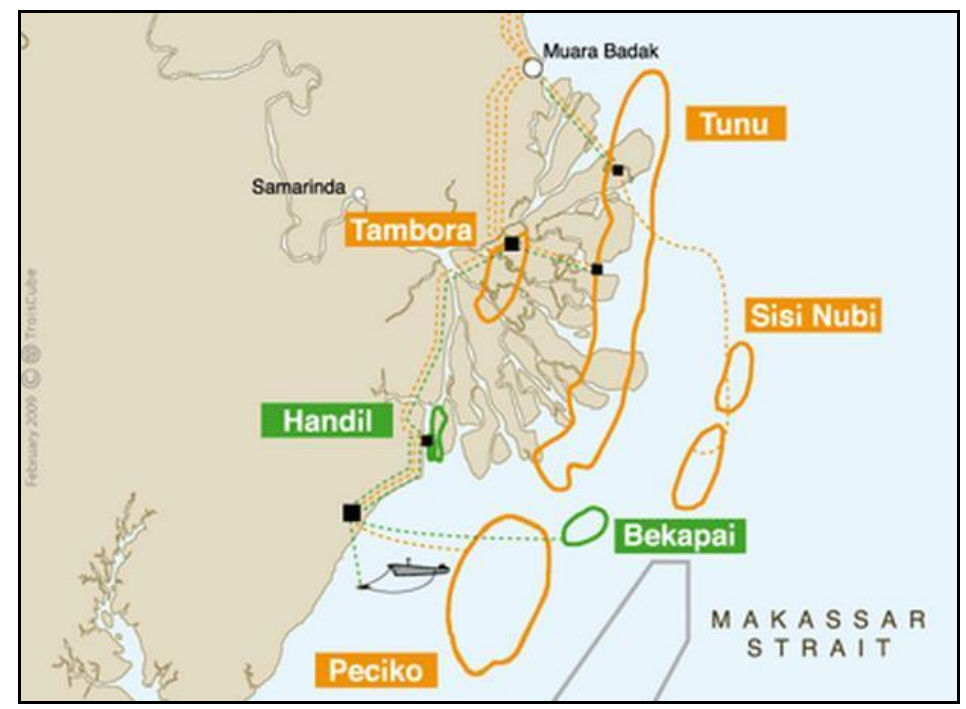

Sumber: Total E\&P Indonesie (2012)

Gambar 1. Lapangan Bekapai

Setelah diresmikannya penandatanganan kontrak kerja sama pengelolaan Blok Mahakam produksi dan pendistribusian minyak dan gas alam lewat pipa bawah laut perlu dilakukan inspeksi secara berkala agar tidak terjadi kerusakan atau bahaya yang dapat terjadi untuk menghindari kerugian material industri itu sendiri serta kerusakan lingkungan di sekitar pipa bawah laut. Penelitian ini diharapkan dapat memberikan informasi kepada pemerintah dalam melakukan inspeksi terhadap pipa bawah laut Lapangan Bekapai secara berkala terutama untuk mengidentifikasi terjadinya hazard dari indikasi adanya free span pada pipa bawah laut menggunakan multibeam echosounder dan side scan sonar.

Indonesia memiliki jalur pipa minyak dan gas pada Lapangan Bekapai, Kalimantan Timur. Untuk pemeliharaan pipa minyak dan gas perlu dilakukan pendeteksian hazard, salah satu di antaranya berupa free span sehingga rumusan masalah dari penelitian ini adalah: "Bagaimana identifikasi hazard berdasarkan kriteria Standar Internasional Det Norske Veritas pada free span pipa bawah laut di Lapangan Bekapai?". Tujuan dari penelitian ini adalah untuk mengidentifikasi hazard menggunakan Standar Internasional Det Norske Veritas berupa free span pipa bawah laut pada jalur pipa minyak dan gas Lapangan Bekapai. Pipa bawah laut pada Lapangan Bekapai, Kalimantan Timur merupakan pipa yang menyalurkan minyak dan gas alam dari satu platform ke platform lainnya sehingga memiliki nilai ekonomis yang penting bagi negara. Dengan demikian pipa tersebut harus terjamin dan terpelihara dari kerusakan atau hazard, di antaranya berupa free span pipa bawah laut. Dengan demikian hasil penelitian ini diharapkan memberikan informasi mengenai ada tidaknya hazard dari free span pipa bawah laut kepada pemerintah dalam menjamin pemeliharaannya. Adapun batasan masalah dari penelitian ini adalah: kriteria yang 
digunakan berdasarkan standar internasional DNV RP-F105, pemodelan 3D menggunakan data dari multibeam echosounder dan side scan sonar, analisis identifikasi ada atau tidak adanya hazard pada pipa gas bawah laut dari indikasi free span yang meliputi informasi posisi, panjang, dan tinggi free span, validasi adanya cekungan di bawah lokasi free span dengan menggunakan profil, dan penelitian ini tidak menggunakan data times series.

\section{METODOLOGI}

Penelitian identifikasi hazard dari hasil data free span menggunakan multibeam echosounder dan side scan sonar dilakukan pada jalur pipa bawah laut Lapangan Bekapai, Kalimantan Timur. Pada Gambar 2 dapat dilihat lokasi penelitian di Lapangan Bekapai yang terletak di sekitar $1^{\circ} 0^{\prime} 0^{\prime}$ LS dan $117^{\circ} 30^{\prime} 0^{\prime}$ BT.

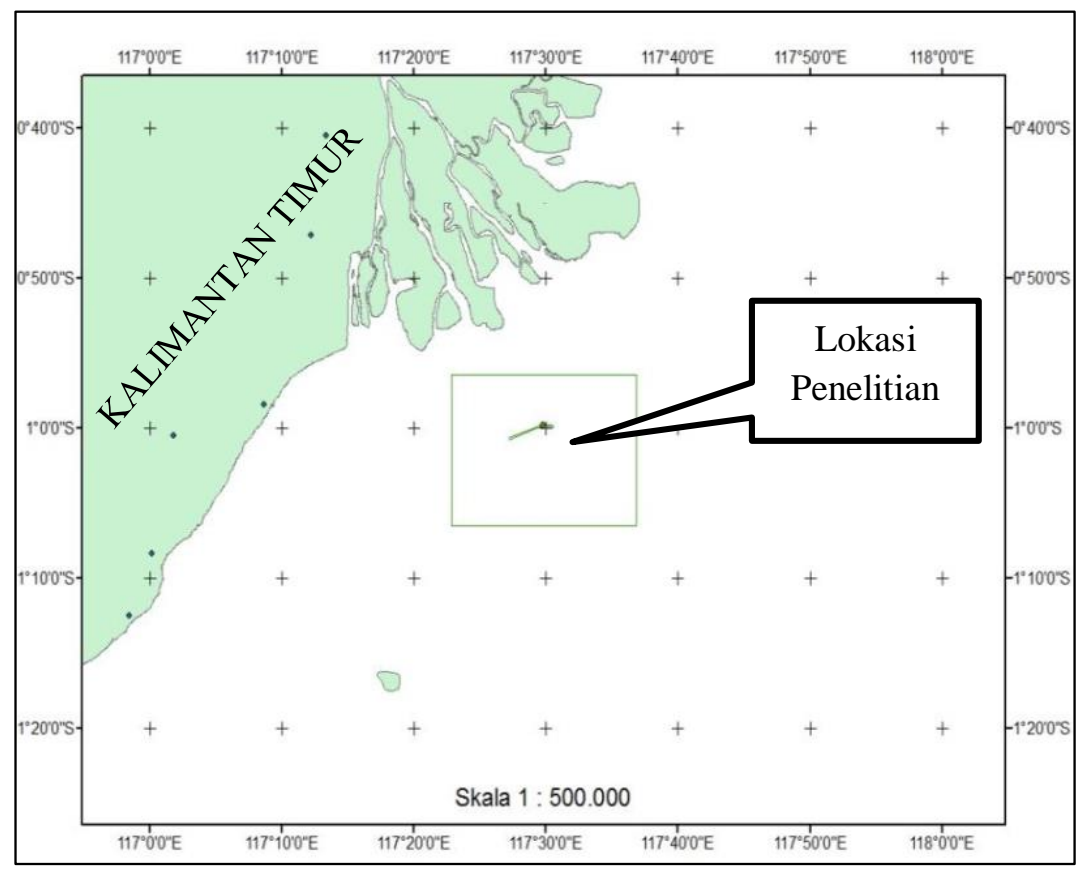

Gambar 2. Lokasi Survei

Data yang digunakan dalam penelitian ini berlokasi di Lapangan Bekapai pada tahun 2012 dan diperoleh dari PT Mahakarya Geo Survey berupa data X, Y, Z multibeam echosounder (format .db) dan raw data dari side scan sonar (format .xtf). Pengolahan dan penyajian data pada penelitian ini menggunakan software yang dapat dilihat pada Tabel 1.

Tabel 1. Software yang digunakan

\begin{tabular}{|c|c|}
\hline Software & Keterangan \\
\hline Qinsy 8.1 & $\begin{array}{l}\text { Untuk pengolahan raw data dari multibeam } \\
\text { echosounder }\end{array}$ \\
\hline SonarWIZ 5 & Untuk pengolahan raw data dari side scan sonar \\
\hline Global Mapper 15 & Untuk overlay MBES dan SSS \\
\hline Surfer 11 & Untuk pemodelan 3D surface MBES \\
\hline $\begin{array}{l}\text { AutoCAD Land Desktop } \\
2009\end{array}$ & Untuk membuat kontur lokasi penelitian \\
\hline PCLP 2002 & Untuk profil free span \\
\hline
\end{tabular}


Metodologi penelitian secara skematik dapat dilihat pada Gambar 3.

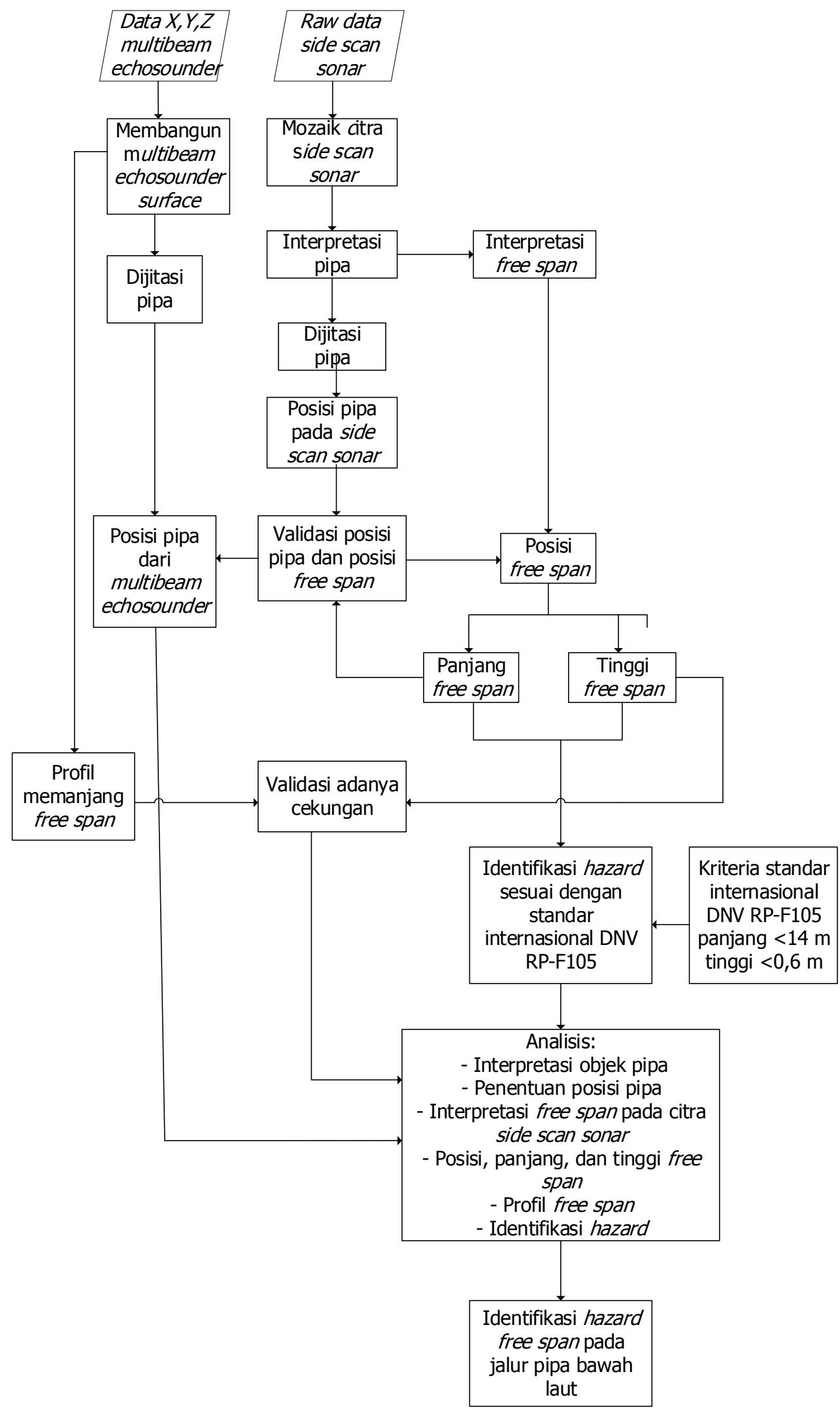

Gambar 3. Metodologi penelitian 
Penjelasan dari diagram alir metodologi penelitian adalah sebagai berikut:

1) Pengumpulan dan Pengolahan Data

pengumpulan dan pengolahan data diperoleh dari PT Mahakarya Geo Survey, yaitu:

Data $\mathrm{X}, \mathrm{Y}, \mathrm{Z}$ multibeam echosounder dan raw data dari side scan sonar.

2) Posisi Pipa dan Free Span

Posisi pipa dan free span diambil dari data multibeam echosounder karena posisi yang diperoleh dari multibeam echosounder dapat dianggap benar dan dijadikan sebagai data posisi primer dibandingkan dengan data side scan sonar.

3) Perkiraan Tinggi Free Span

Perkiraan tinggi free span diambil dari hasil interpretasi side scan sonar karena free span tidak dapat ditentukan dari data multibeam echosounder sepanjang jalur pipa karena prinsip dari multibeam echosounder dilakukan secara vertikal sehingga tidak dapat menerima data yang ada di bawah objek pipa seperti free span.

4) Identifikasi Hazard

Identifikasi hazard menggunakan kritera standar internasional DNV RP F-105. Hasil dari perkiraan panjang dan tinggi free span disesuaikan dengan kriteria tersebut.

\section{HASIL DAN ANALISIS}

\subsection{Interpretasi Objek Pipa}

Hasil dari mozaik citra side scan sonar adalah objek-objek di sekitar lokasi penelitian seperti dapat dilihat pada Gambar 4.

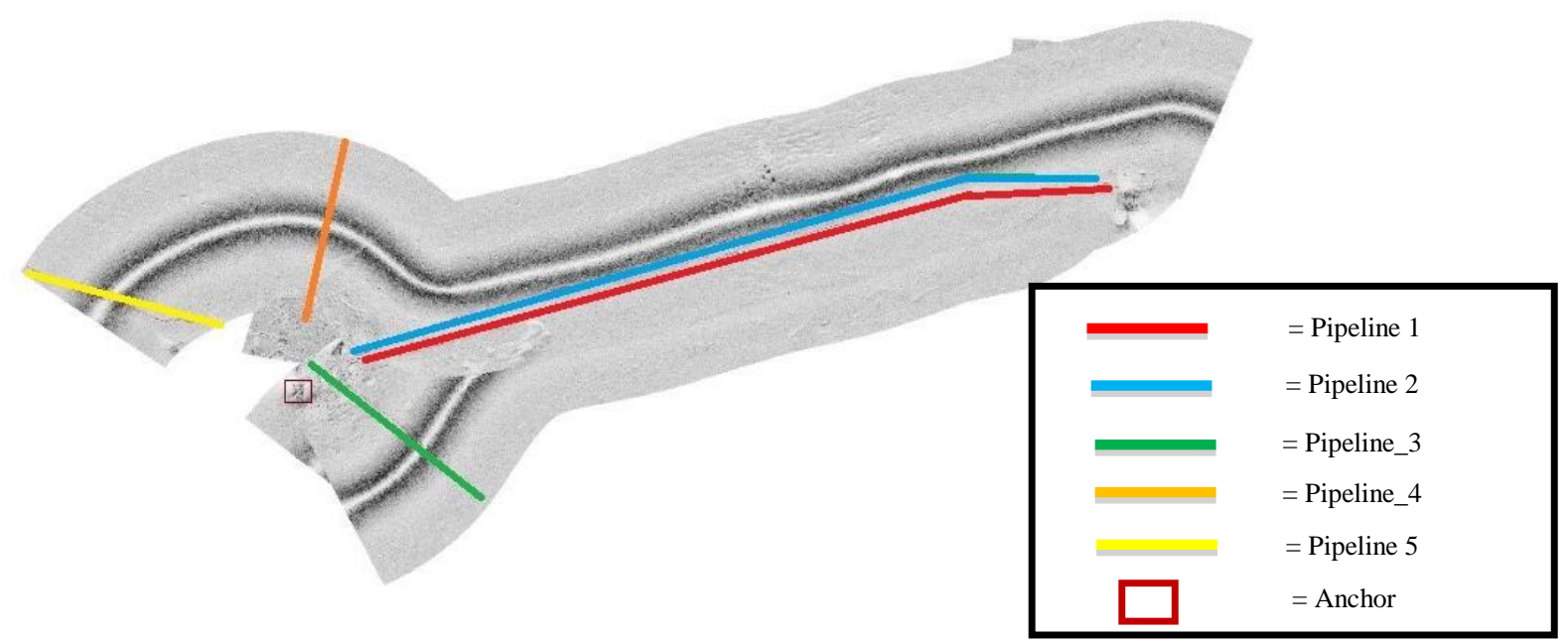

Gambar 4. Hasil interpretasi citra Side Scan Sonar

Objek-objek yang terdapat pada lokasi penelitian yaitu, pipeline dan anchor. Terdapat lima pipeline dan satu anchor pada lokasi penelitian. Untuk mengidentifikasi hazard berupa free span pada pipa bawah laut hanya akan digunakan Pipeline 1 dan Pipeline 2 sebagai sampel penelitian karena memiliki tingkat derajat kehitaman sangat kuat untuk diinterpretasikan objek pipa. Hal ini juga didukung oleh bentuk dan ukurannya yang menyatakan objek yang diinterpretasi adalah pipa seperti dapat dilihat pada Gambar 5, sementara pada Pipeline 3, 4, dan 5 tidak dijadikan sampel penelitian ini karena memiliki tingkat derajat kehitaman bayangan yang lemah dan adanya sand scouring yang terjadi sehingga akan menyebabkan hasil interpretasi menjadi tidak akurat.

Hasil interpretasi yang kurang baik kemungkinan dapat disebabkan oleh beberapa hal seperti kurangnya data sub-bottom profiller dan juga data crossline side scan sonar pada saat 
pengambilan data side scan sonar. Pasang surut juga dapat mempengaruhi towfish pada saat perekaman yang membuat towfish tidak stabil pada posisi yang seharusnya.

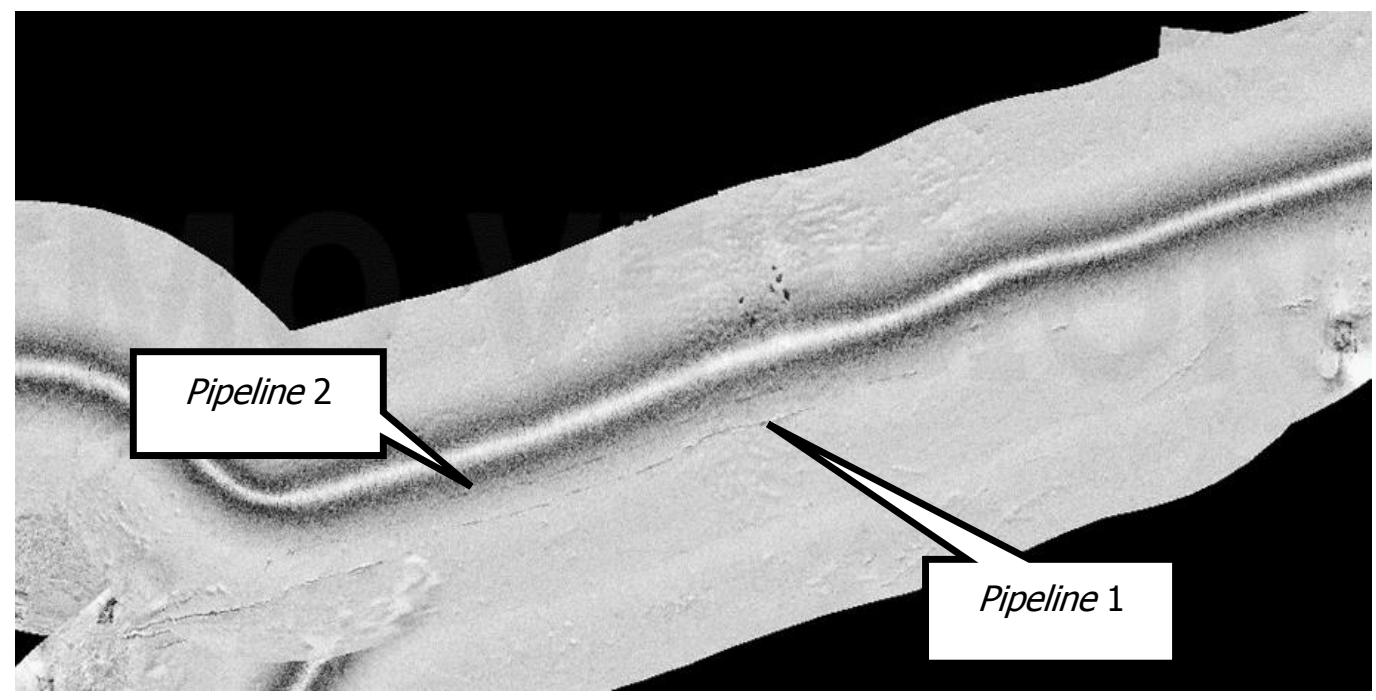

Gambar 5. Pipeline 1 dan pipeline 2

\subsection{Penentuan Posisi Pipa}

Menurut Nugraha dan Yuwono (2014) side scan sonar mengakuisisi data dengan prinsip towing atau ditarik dengan tow cable, sehingga dapat dikatakan positioning untuk side scan sonar tidak langsung terhubung dengan GPS melainkan melalui perantara suatu sistem tambahan yaitu ultra short baseline (USBL). Hal ini memungkinkan terjadinya perambatan kesalahan, yaitu kesalahan offset transduser USBL terhadap GPS dan kesalahan sistem USBL sendiri terhadap side scan sonar, sehingga berdampak pada kualitas posisi pipa dan free span-nya yang kurang bisa diandalkan. Menurut Lekkerkerk dkk. (2006) sistem multibeam echosounder menggunakan sistem mounted di mana tidak terdapat sistem lain untuk mengintegrasikan GPS dengan transduser. Yang perlu diperhatikan adalah offset transduser multibeam echosounder terhadap GPS sehingga posisi yang diperoleh dapat dianggap benar dan dijadikan sebagai data posisi primer. Berdasarkan pernyataan tersebut maka posisi pipa tidak diambil dari citra side scan sonar, tetapi dari hasil dari multibeam echosounder. Pada Gambar 6 dapat dilihat posisi pipa yang didapatkan dari kedua sistem yang digunakan.

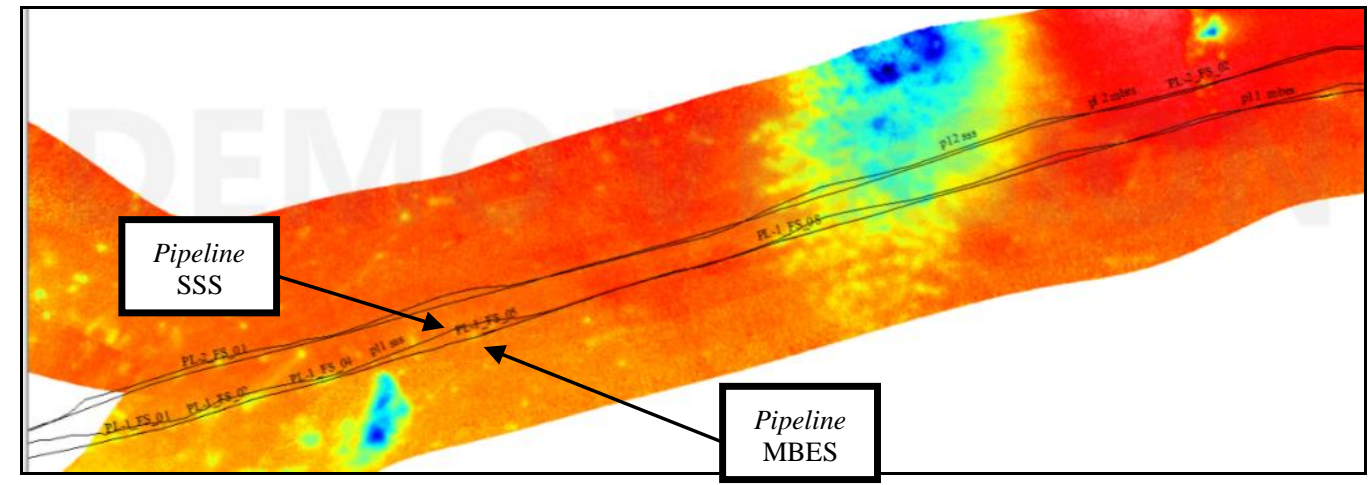

Gambar 6. Posisi pipa dari Multibeam Echosounder dan Side Scan Sonar

Pada Gambar 6 dijelaskan posisi pipa pada multibeam echosounder dan side scan sonar tidak berhimpit, pada posisi pipa dari multibeam echosounder memiliki bentuk yang lebih 
teratur dibandingkan dengan posisi pipa dari side scan sonar. Dengan demikian posisi pipa yang digunakan adalah hasil dari data multibeam echosounder.

\subsection{Interpretasi Free Span pada Citra Side Scan Sonar}

Menurut Erwanti dkk. (2016) kondisi free span dikenali dari adanya bayangan yang lebih jauh dari objek dibandingkan dengan bayangan objek pipa yang tidak mengalami kondisi free span. Dengan melihat adanya bayangan yang lebih jauh maka pada Pipeline 1 dapat dikenali adanya sembilan free span dan pada Pipeline 2 ada dua free span. Berikut ini dapat dilihat pada Gambar 7 dan 8 sampel hasil interpretasi free span pada Pipeline 1 dan Pipeline 2.

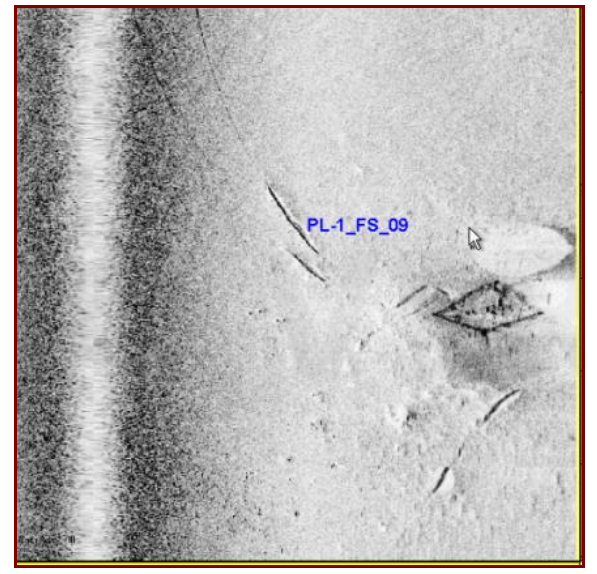

(a)

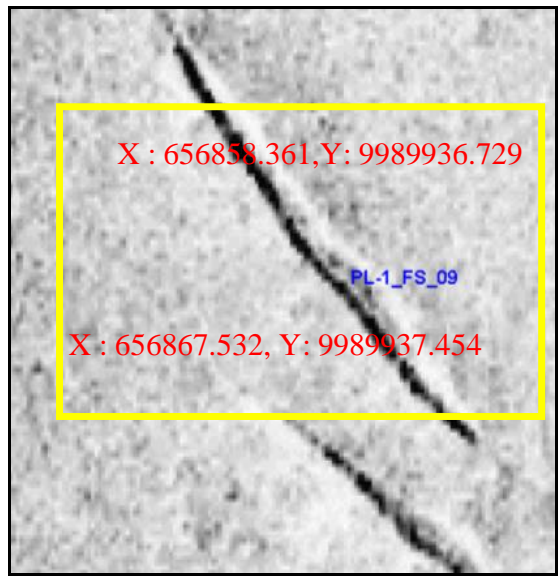

(b)

Gambar 7. Lokasi Free Span PL-1_FS_09

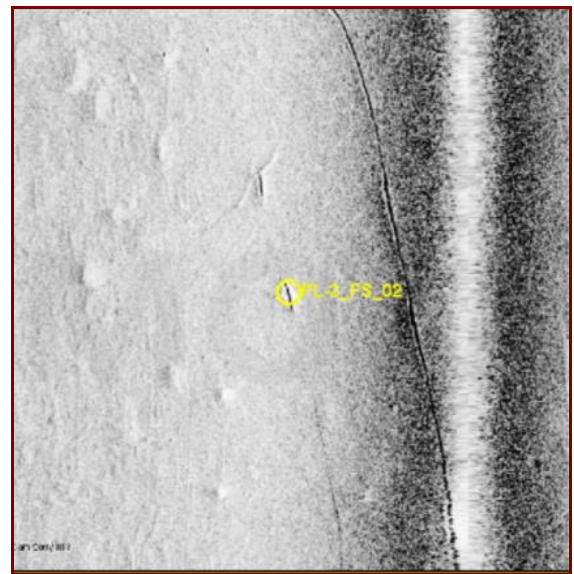

(a)

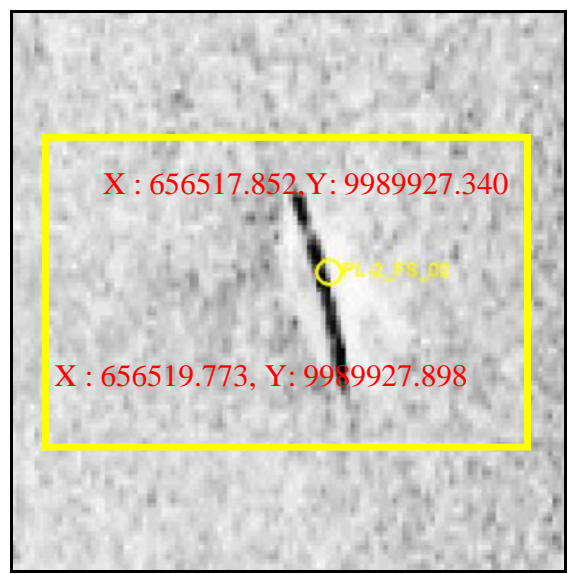

(b)

Gambar 8. Lokasi Free Span PL-2_FS_02

Pada Pipeline 2 hanya ada dua free span yang dapat diinterpretasi, karenanya masih perlu investigasi lebih lanjut untuk memastikan apakah karena masalah dari citra side scan sonar itu sendiri atau memang tidak adanya free span. Perlunya data dari crossline side scan sonar dan data sub-bottom profiller untuk lebih memastikan terjadinya free span. 


\subsection{Posisi, Panjang, dan Tinggi Free Span}

Posisi kedua titik ujung free span yang dianggap benar diambil dari data multibeam echosounder. Panjang free span dapat ditentukan dari kedua titik ujung free span, namun untuk tinggi free span tidak dapat ditentukan dari data multibeam echosounder sepanjang jalur pipa karena prinsip dari multibeam echosounder dilakukan secara vertikal sehingga tidak dapat menerima data yang ada di bawah objek pipa seperti free span. Dengan demikian perkiraan tinggi free span yang digunakan berdasarkan hasil interpretasi citra side scan sonar. Hasil identifikasi berupa posisi kedua titik ujung, panjang dan tinggi free span pada Pipeline 1 dan 2 dapat dilihat Pada Tabel 2.

Tabel 2. Hasil posisi, panjang, dan tinggi Free Span

\begin{tabular}{|c|c|c|c|c|c|c|c|}
\hline \multirow{2}{*}{ No } & Span & \multicolumn{2}{|c|}{ Titik awal } & \multicolumn{2}{c|}{ Titik akhir } & Panjang & \multirow{2}{*}{$\begin{array}{c}\text { Maksimum } \\
\text { span }(m)\end{array}$} \\
\cline { 3 - 6 } & $I D$ & $X(m)$ & $Y(m)$ & $X(m)$ & $Y(m)$ & tinggispan $(m)$ \\
\hline 1 & PL-1_FS_01 & 655717,219 & 9989663,818 & 655719,463 & 9989664,319 & 2,30 & 0,10 \\
\hline 2 & PL-1_FS_02 & 655770,357 & 9989678,113 & 655777,053 & 9989680,161 & 7,00 & 0,16 \\
\hline 3 & PL-1_FS_03 & 655799,121 & 9989686,671 & 655804,327 & 9989688,123 & 5,40 & 0,17 \\
\hline 4 & PL-1_FS_04 & 655848,460 & 9989701,500 & 655854,505 & 9989703,316 & 6,30 & 0,16 \\
\hline 5 & PL-1_FS_05 & 655974,065 & 9989739,562 & 655976,643 & 9989740,364 & 2,70 & 0,12 \\
\hline 6 & PL-1_FS_06 & 656604,446 & 9989916,201 & 656612,914 & 9989916,938 & 8,50 & 0,21 \\
\hline 7 & PL-1_FS_07 & 656445,350 & 9989878,830 & 656450,059 & 9989880,184 & 4,90 & 0,17 \\
\hline 8 & PL-1_FS_08 & 656198,571 & 9989807,718 & 656206,626 & 9989810,103 & 8,40 & 0,18 \\
\hline 9 & PL-1_FS_09 & 656858,361 & 9989936,729 & 656867,532 & 99899937,454 & 9,20 & 0,24 \\
\hline 10 & PL-2_FS_01 & 655770,130 & 9989712,336 & 655774,078 & 9989713,442 & 4,10 & 0,09 \\
\hline 11 & PL-2_FS_02 & 656517,852 & 9989927,340 & 656519,773 & 9989927,898 & 2,00 & 0,08 \\
\hline
\end{tabular}

Panjang dan tinggi rata-rata dari 11 free span yang terdeteksi pada Pipeline 1 dan 2 yaitu dengan panjang 5,53 $\mathrm{m}$ dan tinggi $0,15 \mathrm{~m}$, minimum panjang dan tinggi free span pada $\mathrm{PL}-$ 2_FS_02 dengan panjang 2,0 $\mathrm{m}$ dan tinggi 0,08 $\mathrm{m}$ dan panjang dan tinggi maksimum free span pada PL-1_FS_09 dengan panjang 9,2 $\mathrm{m}$ dan tinggi $0,24 \mathrm{~m}$.

\subsection{Profil Free Span}

Tinggi dari free span yang terdeteksi masih merupakan perkiraan dari hasil interpretasi side scan sonar. Karena data crossline side scan sonar dan sub bottom profiller tidak tersedia maka pada penelitian ini untuk memastikan adanya cekungan pada lokasi free span dari data posisi multibeam echosounder yang digunakan sebagai posisi sebenarnya pada sampel pipa di lokasi penelitian Pipeline 1 dan Pipeline 2, berupa sekumpulan titik-titik dan dijadikan data kontur. Data multibeam echosounder yang dipakai hanya beberapa data di sekitar lokasi penelitian yang diambil sebagai sampel untuk dijadikan kontur. Berikut ini dapat dilihat pada Gambar 9 kontur dari salah satu free span pada PL-1_FS_09. 


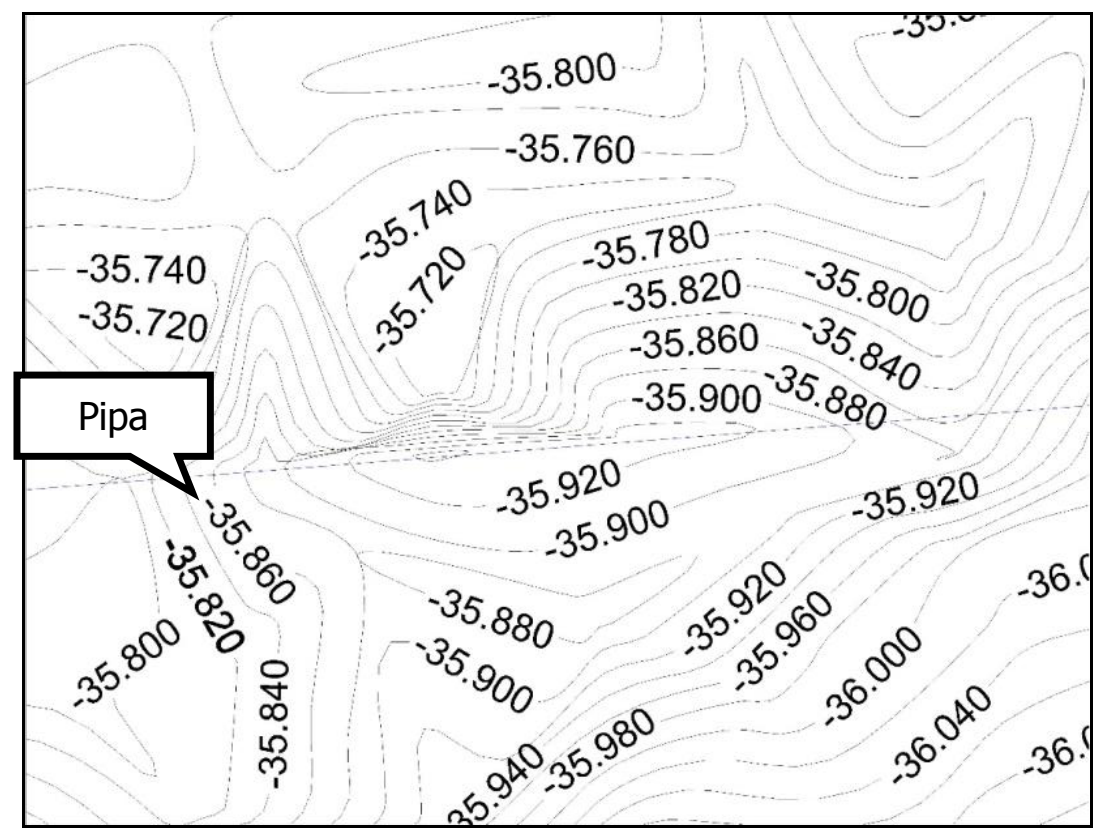

Gambar 9. Kontur di lokasi Free Span PL-1_FS_09

Kontur yang dihasilkan di sekitar 11 lokasi free span yang terdeteksi memperlihatkan adanya cekungan. Masing-masing dari free span yang terdeteksi dibuat profil memanjang sesuai dengan hasil dari interpretasi panjang free span untuk mempertegas adanya cekungan di bawah pipa. Berikut ini dapat dilihat pada Gambar 10 salah satu profil free span pada PL1_FS_09.

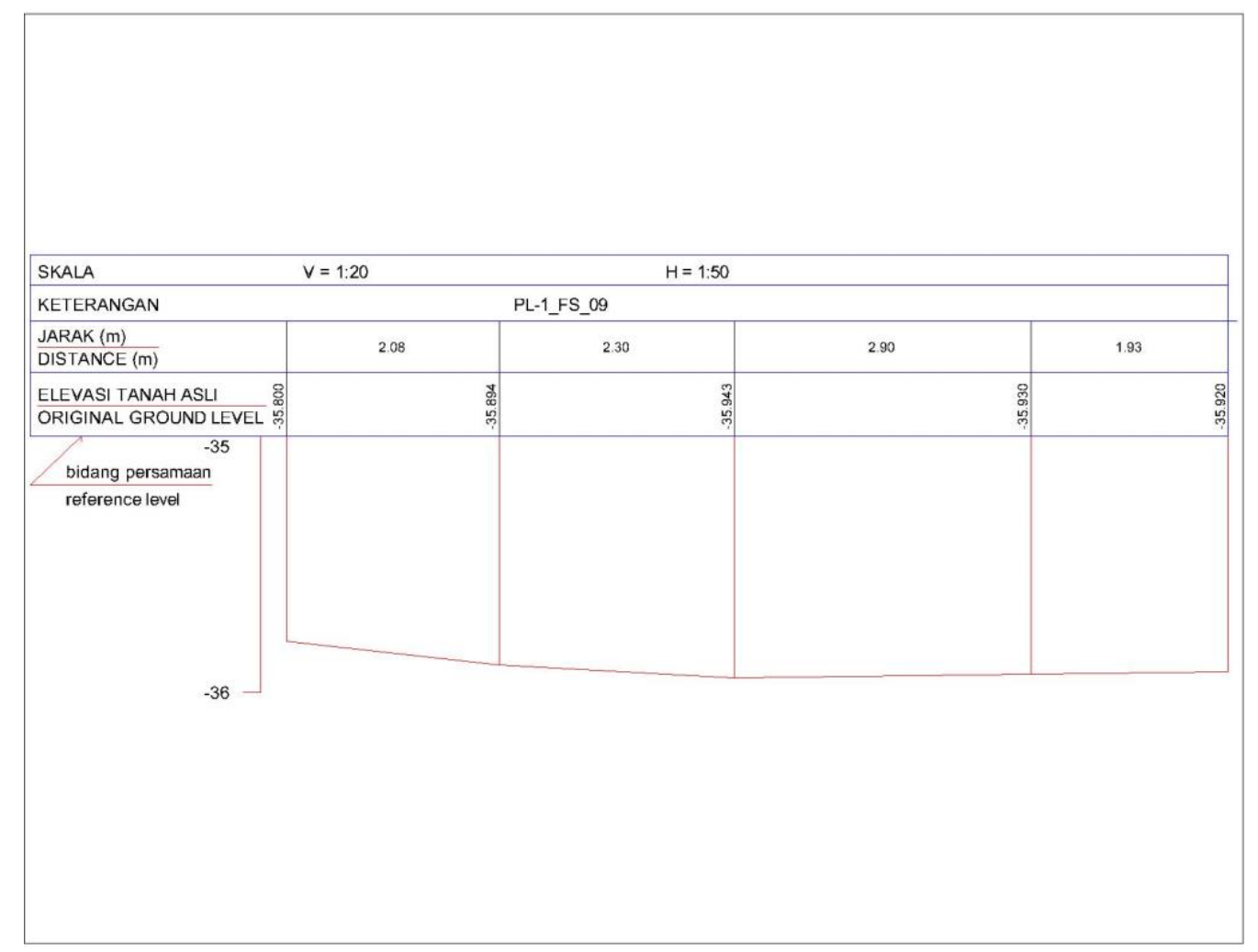

Gambar 10. Profil Free Span PL-1_FS_09 


\subsection{Analisis Identifikasi Hazard}

Untuk mengidentifikasi hazard berupa free span pipa bawah laut digunakan standar internasional DNV RP-F105. Dari kriteria DNV RP F-105 disebutkan batas maksimum free span pada pipa bawah laut yang sudah beroperasi, yaitu dengan panjang kurang dari $14 \mathrm{~m}$ dan tinggi kurang dari 0,6 $\mathrm{m}$. Dari hasil perkiraan panjang dan tinggi maksimum free span yang diidentifikasi berada pada PL-1_FS_09 dengan koordinat titik-titik ujung, titik awal $(656858,361 ; 9989936,729) \mathrm{m}$, titik akhir $(656867,532 ; 9989937,454) \mathrm{m}$, sehingga ke 11 free span yang diidentifikasi masih dalam kategori aman atau bukan merupakan hazard pipa bawah laut, karena masih di bawah batas maksimum yang sesuai dengan standar internasional DNV RP-F105.

\section{KESIMPULAN}

Berdasarkan penelitian identifikasi hazard dari hasil data free span pada jalur pipa bawah laut Lapangan Bekapai menggunakan data multibeam echosounder dan side scan sonar dapat disimpulkan bahwa terdapat sembilan free span pada Pipeline 1 dan dua free span pada Pipeline 2. Rata-rata panjang dan tinggi free span adalah 5,529 m dan 0,15 m. Panjang dan tinggi free span minimum terdapat pada PL-2_FS_02 dengan panjang 2,0 $\mathrm{m}$ dan tinggi 0,08 $\mathrm{m}$, sedangkan panjang dan tinggi free span maksimum pada PL-1_FS_09 dengan panjang 9,2 $\mathrm{m}$ dan tinggi 0,24 $\mathrm{m}$. Sesuai dengan kriteria standar internasional DNV RP F-105 dari lokasi free span yang diidentifikasi pada sampel Pipeline 1 dan Pipeline 2 masih dikategorikan aman atau tidak ada hazard yang ditimbulkan dari free span pada pipa bawah laut lokasi penelitian. Pipeline 1 dan Pipeline 2 dijadikan sampel pada penelitian ini karena memiliki tingkat derajat kehitaman bayangan yang kuat dibandingkan dengan Pipeline 3, 4, dan 5. Di samping itu terdapat sand scouring pada Pipeline 3, 4, dan 5 yang mempersulit interpretasi. Kontur dan profil pada free span merupakan perkiraan berdasarkan titik-titik di sekitar lokasi free span sehingga tinggi free span tidak dapat dihitung berdasarkan profil yang dibangun. Perkiraan tinggi free span diperoleh dari hasil interpretasi citra side scan sonar. Hasil dari kontur dan profil di sekitar lokasi free span membuktikan adanya cekungan yang memperkuat terjadinya free span.

\section{UCAPAN TERIMA KASIH}

Ucapan terima kasih yang sebesar-besarnya disampaikan kepada PT Mahakarya Geo Survey dan seluruh pihak yang membantu dalam proses penelitian ini.

\section{DAFTAR PUSTAKA}

Erwanti, S.R., Sasmito, B., Amarrohman, F. J. (2016). Analisis Free Span pada Jalur Pipa Bawah Laut Menggunakan Multibeam Echosounder dan Side Scan Sonar": Studi Kasus Pipa Gas Transimisi SSWJ (South Sumatera West Java) Jalur Pipa Gas Labuan MaringgaiMuara Bekasi PT Perusahaan Gas Negara Persero (Tbk). Jurnal Geodesi Undip, Vol. 5, No. 1.

Hanimadhani, A. (2016). Analisa Geohazard Terhadap Jalur Pipa Gas Bawah Laut PGN: Labuhan Maringgai-Muara Bekasi. Tugas Akhir Teknik Kelautan ITS, Surabaya. Dipetik pada 5 Agustus 2017 dari http://digilib.its.ac.id/ITS-Undergraduate$3100012045700 / 18497$. 
Lekkerkerk, H. J., Velden, R. V., Haycock, T., Jansen, P., Vries, R. D., Waalwijk, P. V. (2006). Handbook of Offshore Surveying Volume One: Preparation \& Positioning. London: Clarkson Research Service Limited.

Nugraha I.M.D.S. dan Yuwono (2014). Studi Aplikasi Multibeam Echosounder dan Side Scan Sonar untuk Mendeteksi Free Span pada Saluran Pipa Bawah Laut: Studi Kasus Laut Jawa. Jurnal Teknik Geomatika, Vol. 10, No.1

Prayoga, D.G.S. (2013). Langkah Analisa Penilaian Risiko Offshore Pipeline Secara Sederhana. Dipetik 1 April 12017 dari http://maritimengineering.blogspot.co.id.

Sumarsono. (2011). Total E\&P Indonesia Ukir Sejarah Baru. Dipetik 5 Agustus 2017 dari http://www.kaltim.tribunnews.com.

Veritas Offshore Technology and Services A/S. (2006). DNV RP F105 "Free Spanning Pipelines". Norway; DNV.

Wibisono, S.G. (2016). Minyak dan Gas Masih Melimpah dari Senipah. Dipetik 5 Agustus 2017, dari http://www.tempo.co. 